\title{
Broad-scale modelling of coastal wetlands: what is required?
}

\author{
Loraine McFadden · Tom Spencer • \\ Robert J. Nicholls
}

(C) Springer Science+Business Media B.V. 2007

\begin{abstract}
A Wetland Change Model has been developed to identify the vulnerability of coastal wetlands at broad spatial (regional to global (mean spatial resolution of $85 \mathrm{~km}$ )) and temporal scales (modelling period of 100 years). The model provides a dynamic and integrated assessment of wetland loss, and a means of estimating the transitions between different vegetated wetland types and open water under a range of scenarios of sea-level rise and changes in accommodation space from human intervention. This paper is an overview of key issues raised in the process of
\end{abstract}

Guest editors: P. Viaroli, P. Lasserre and P. Campostrini. Lagoons and Coastal Wetlands in the Global Change Context: Impacts and Management Issues

L. McFadden ( $\square)$

Flood Hazard Research Centre, Middlesex

University, Queensway, Enfield EN3 4SA, UK

e-mail: L.McFadden@mdx.ac.uk

T. Spencer

Cambridge Coastal Research Unit, Department of Geography, University of Cambridge, Downing Place, Cambridge CB2 3EN, UK

e-mail: tom.spencer@geog.cam.ac.uk

\section{R. J. Nicholls}

School of Civil Engineering and the Environment, University of Southampton, Highfield Southampton SO17 1BJ, UK

e-mail: r.j.nicholls@soton.ac.uk quantifying broad-scale vulnerabilities of coastal wetlands to forcing from sea-level rise discussing controlling factors of tidal range, sediment availability and accommodation space, identification of response lags and defining the threshold for wetland loss and transition.

\section{Introduction}

Coastal zones are currently experiencing intense and sustained environmental pressures from a range of natural, semi-natural and anthropogenic drivers (Mitsch \& Gosselink, 2000). Increased resource use, environmental protection and the incorporation of social and equity issues into decision-making must evolve in the context of physical and ecological systems which show multiscale dynamics and considerable uncertainties in likely response to near future environmental change (Poff et al., 2002; Morris et al., 2002). Both short-term and geological records show that coastal wetlands are particularly sensitive to change within the coastal zone (Allen, 2000; Schwimmer \& Pizzuto, 2000; French \& Spencer, 2002). Given such sensitivities, changes in wetland extent, position and type can be expected as accelerated sea-level rise increases forcing on wetland systems. Specific wetland loss mechanisms may include a range of natural processes, 
including edge erosion and retreat; internal dissection by the expansion of creek networks and surface ponds; changes in inundation frequency, waterlogging and in situ vegetative and root decay, and also human modification of marsh topography, sedimentology, ecology and hydrology (Mendelssohn \& Morris, 2000). Within these contexts, this paper presents a new broad-scale wetland model which focusses upon the impact of relative sea-level rise on wetlands within the coastal zone.

Improving on earlier broad-scale assessments of wetland vulnerability (Hoozemans et al., 1993; Nicholls et al., 1999) and underpinned by a greatly improved global wetlands database (Vafeidis et al., 2004), the Wetland Change Model (i) provides a dynamic and integrated assessment of regional to global patterns of coastal wetland vulnerability and wetland loss; (ii) determines the ecological sensitivity of different wetland types to environmental forcing and the likelihood of transition to other wetland types and (iii) permits the assessment of the relative importance of sea-level rise, sediment supply and coastal protection measures in affecting wetland vulnerability. This model represents one module within the DIVA integrated assessment model for coastal areas (Dynamic Interactive Vulnerability Assessment)-developed within the EU-funded DINASCOAST Project (Dynamic and Interactive Assessment of National, Regional and Global Vulnerability of Coastal Zones to Climate Change and Sea-Level Rise, www.dinas-coast.net). The DIVA tool has been designed to assess impact and vulnerability of the coastal zone to sea-level rise at regional to global scales and is driven by a set of internally consistent 'mid-term' (until 2100) scenarios of sea-level rise and socio-economic drivers of societal sensitivity to plausible impacts of accelerated sea-level rise and adaptive capacity (Hinkel \& Klein, 2003). DIVA identifies coastal units that are particularly vulnerable to sea-level rise and adverse human interventions and allows for the evaluation of a range of response options (McFadden et al., in press).

Following the aim of the DINAS-COAST Project, the Wetland Change Model transforms a dynamic assessment of wetland vulnerability into patterns of wetland loss and transition. It seeks to capture the broad-scale response of wetlands to sea-level rise, integrating key drivers of wetland behaviour including human impacts such as dike construction or wetland nourishment (increasing sediment supply). This paper discusses key concepts raised in the process of modelling broad-scale wetland behaviour, underlining the problems of analysis at such spatial scales. Future developments are also considered, especially how this type of approach could be linked to other broad-scale monitoring efforts.

\section{Broad-scale modelling of wetland behaviour}

Modelling broad-scale wetland response to sealevel rise is important from a number of perspectives. In the first instance it strengthens our understanding of the mechanisms which control the behaviour of the wetland system as a largescale unit within the physical landscape. Identifying 'hotspots' of wetland loss and a broad-scale assessment of levels of wetland vulnerability enables coastal managers and national organisations to make decisions on the best use of limited resources (Hammar-Klose \& Thieler, 2001). Such modelling forms a basis from which effective plans can be developed to manage wetland change. In addition to this spatial dimension, broad-scale modelling is important to our understanding of long-term trajectories of future marsh behaviour. Important feedback mechanisms at longer-time scales (e.g. elevation/accretion relationships) mean that short-term measurements cannot be simply extrapolated to identify behavioural trends within a medium- to longterm temporal framework.

The Global Vulnerability Assessment (or GVA) and its subsequent revision provided the first worldwide estimate of both socio-economic and ecological implications of accelerated sealevel rise (Hoozemans et al., 1993; Nicholls et al., 1999). Based on a range of simple assumptions concerning rates of sea-level rise, subsidence and the response of the wetlands to sea-level forcing, the GVA gives a first-order perspective on wetland loss rates. However, the datasets have incomplete coverage, only three wetland types are considered, and wetland losses are only 
controlled by tidal range and accommodation space. While most calculations were conducted at a national scale, only results aggregated to a regional or global level could be considered valid (Nicholls et al., 1999).

Mass-balance models that focus on vertical adjustment of wetlands given accelerated sealevel rise have identified a number of controls on wetland response to environmental forcing factors: e.g. Severn Estuary, UK (Allen, 1990); North Norfolk coast, UK; Hut Marsh, Scolt Head Island (French, 1993); Venice Lagoon (Day et al., 1999); and wetlands of Louisiana, USA (Koch et al., 1990). Useful as these analyses are in defining the envelope of response, they only give a one-dimensional view of wetland-sea-level rise relations. Complex patterns of sedimentation mean that such models may not accurately represent the true sediment volumes required to enable such systems to keep pace with sea-level rise (French et al., 1995). Other studies have considered, and in some cases modelled, the landward retreat of saltmarshes under present, and expected near-future, rates of sea-level rise. Thus, for example, open coasts marshes in Essex, England (Harmsworth \& Long, 1986; Reed, 1988), the marshes of the eastern Scheldt, Netherlands (Oenema \& DeLaune, 1988) and salt marshes in the Gulf of Gabes, Tunisia (Oueslati, 1992) have provided a range of information on erosion and accretion along seaward marsh margins. In addition, it has been argued that floristically-rich upper marshes will disappear under the landward retreat of enclosing barriers (French, 1993). Most detailed studies of wetland loss of the type outlined above are typically local and relatively short-term in nature. Whilst such studies can be a useful means of calibration for broad-scale analysis, there is the significant problem of upscaling observations to the regional scale and longer time periods appropriate to modelling the broad-scale response of the system (Mitsch \& Day, 2004). These problems have been addressed by the development of Landscape Simulation Models which are proving effective in assessing both the present and expected nearfuture distributions of wetland habitat types, taking into account both vertical and horizontal adjustments. Such models use hydrologic sub- models to distribute fluxes of water, nutrients and sediments over a grid of several thousand individual cells. Each cell incorporates a sub-model for plant production and soil formation which, alongside the hydrologic sub-model, determines the vegetation community. With changing environmental conditions, each cell is repeatedly interrogated by a 'habitat switcher' which resets the vegetation community if certain thresholds to inundation, soil chemistry and salinity are exceeded. Mapping expected environmental change in the Mississippi delta has been achieved in this way (Reyes et al., 2000; Martin et al., 2002). However, the computation effort required for this type of modelling approach precludes its current use as a widespread broad-scale tool for wetland analysis.

The Wetland Change Model presented within this paper seeks to engage with both levels of the current analysis of wetland performance identified above, identifying the key dynamics of wetland response emerging from small-scale analyses, and building a model which can then be tested, in part, against the modelling of changing wetland extent at the landscape scale. Fundamental to this characterisation is a conceptual model that defines the parameters that control wetland behaviour (Fig. 1). This paper examines the primary components of this conceptual model; in doing so, the challenges of broad-scale modelling are discussed.

\section{Identifying environmental factors driving broad-scale wetland change}

The DIVA Wetland Change Model, following earlier models, is based on the assumption that wetland response to external forcing such as sealevel rise involves both horizontal migration and vertical adjustment (Phillips, 1986; Nicholls et al., 1999; Allen, 2000). Vertical and horizontal changes may act independently of each other, but system behaviour must be considered as the synergistic response of both components. This integrated response of the system is modelled using three broad, yet critical, environmental forcing factors. 
Fig. 1 Wetland Change Model

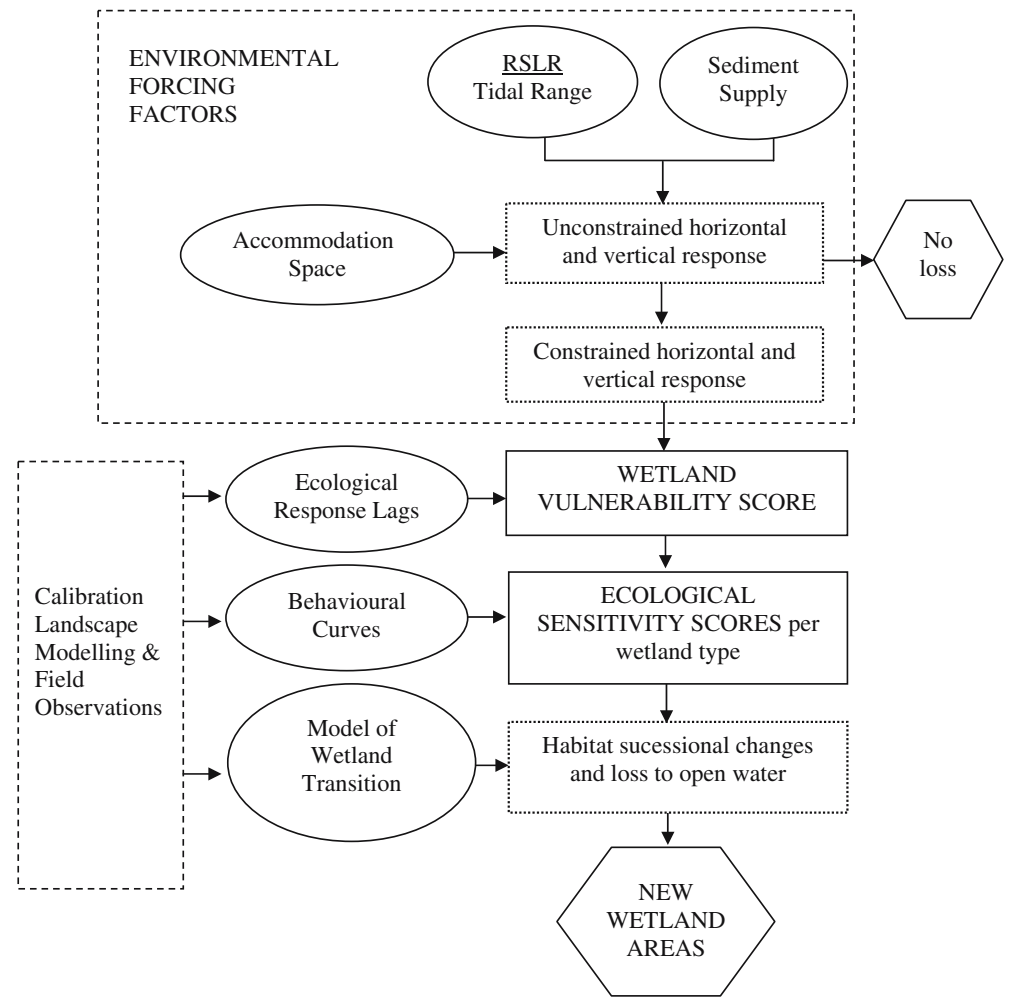

Ratio of relative sea-level rise to tidal range

A primary environmental forcing factor in driving vulnerability is the ratio of the rate of relative sealevel rise to tidal range. When sea-level rise is sudden and of high magnitude, as might result from sudden tectonic subsidence or high magnitude events such as tsunamis, a wetland may be completely submerged. Much more frequently, however, wetlands are subjected to slow rates of relative sea-level rise caused by eustatic factors and geological subsidence. Rather than submergence, the immediate impact of such gradual increases in sea level is a change in the nature of tidal flooding or hydroperiod (Reed, 1995). Hydroperiod is the cumulative inundation of surfaces due both to periodic flooding and to aperiodic tidal surge or high water levels associated with tidal surge or high river water flows and pulsed inputs of river sediments (Day et al., 1997). If wetlands are subject to a rise in relative sealevel without equal increases in elevation of the system, the duration and depth of tidal flooding will increase and communities can revert to a species composition typical of lower position in the tidal frame. In this situation tidal range is particularly significant in determining the vulnerability of the system to sea-level rise. It has been argued (Stevenson et al., 1986) that a wetland maintaining equilibrium under a large tidal range may have greater resilience towards the impacts of sea-level rise than a system existing within a narrower range of tidal fluctuation. As a result, modelling the combined impact of sea-level rise and tidal range is important in determining wetland response to sea-level forcing. Changes in storminess, direction of wave approach and tidal range are likely to accompany changes in mean sea level, but it is not possible to consider these effects in the current model framework.

\section{Sediment supply}

The long-term stability of coastal wetlands is also determined by the ability of wetland surfaces to maintain relative position in the tidal frame, thus keeping pace with the rate of sea-level rise (French, 1993). Regional trends in sediment 
supply are difficult to estimate due to their localised and highly variable temporal behaviour. There are often multiple sources of fine sediments (including riverine, cliff and offshore sources) on low-lying coasts and it is frequently difficult to isolate the contribution of particular sources, to assess the relative importance of local versus long-distance fine sediment transport and to differentiate between primary sediment supply and the re-mobilisation of previously transported sediments. In developed regions, human influences on the natural supply of sediment may significantly affect the response of wetlands over the long term. The submergence of Mississippi wetlands is partly due to the nature of catchment land management practices over the last 200 years that have reduced the supply of sediment to the inter-distributary bays. Similarly, more locally, coastal protection works often modify sediment transport pathways and sediment circulation systems.

A number of physical and human parameters are used within DIVA Wetland Change model to assess the impact of varying sediment supply on wetland vulnerability (Fig. 2). However, given the complexities of impact and response between sediment supply and wetland change, a comprehensive analysis of this forcing factor is not possible at the broad scale. A number of constraints on the model exist. Estimating the supply of a specific sediment type such as sand, mud, organic or inorganic, for example, cannot adequately be considered, so that only fine-grained sediment appropriate to the wetlands being studied can be assessed. Whilst it is clear that below-ground processes play an important role in coastal wetland stability (Nyman et al., 1995), the volume of sediment accreting on a wetland surface is the primary determinant of system response within the model. Sediment supply from in situ accumulation of organic sediments (Cahoon \& Reed, 1995; Middleton \& McKee, 2001; Rooth et al., 2003) or from external, inorganic inputs (French \& Spencer, 1993; Christiansen et al., 2000) or a combination of the two, are used to characterise the impact of the environmental forcing factor within the DIVA model.

\section{Accommodation space}

The third driving factor is lateral accommodation space: given sufficient sediment supply to the system, this parameter is a key factor in determining the horizontal migration responses of wetlands. Coastal geomorphology has a major impact on accommodation space, where areas of high relief with steep coastal gradients reduce or remove the capacity for landward migration. Landward margins that have been fixed through coastal defence structures also effectively reduce the accommodation space, preventing horizontal migration.

\section{Summary of environmental forcing factors}

The Wetland Change Model combines environmental forcing on both horizontal and vertical response to give an assessment of the vulnerability of the total wetland area (Fig. 1). The model incorporates a number of physical (e.g. tidal range and sediment supply) and socio-economic forcing factors (e.g. removal of accommodation space by building seawalls and dikes). It is multidimensional in its characterisation of wetland vulnerability. It extends and refines the range of parameters that have been used in previous global assessments by taking account of all the main drivers of wetland change at broad scales. The model further builds on this characterisation by including a weighting component for each forcing
Fig. 2 Characterising sediment supply within the DIVA Wetland Change Model

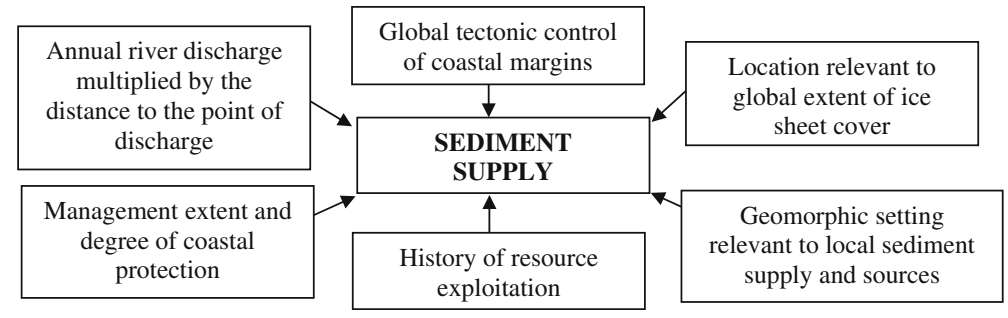


Table 1 The global weighting component for the environmental forcing factors

Ratio of relative sea-level rise to tidal range $\quad 0.5$

Sediment supply $\quad 0.3$

Accommodation space $\quad 0.2$

factor (Table 1). The relative weighting of the environmental forcing factors reflect the importance of the parameter and the confidence with which it can be estimated at the broad-scale. This weighting component facilitates a greater resolution of system variability, recognising that each environmental forcing factor may exert a variable influence on wetland response depending on regional conditions.

\section{Wetland response timescales}

The response of a wetland to environmental stresses is not necessarily immediate. Rather, it is likely to be due to a combination of current and previous ecological states. This time lag between a forcing event and its geomorphological and/or ecological expression is dependent on habitat type. As a key aspect of the behaviour of wetlands to sea-level forcing, it is important that appropriate wetland response timescales are considered within broad-scale analyses. Incorporating such ecological lag time within the Wetland Change Model involves two conceptual developments: (1) global coastal wetland typology and (2) establishing relative response times for each wetland type.

Geographic variation in vegetation zonation has traditionally been used to form the basis for coastal wetland classifications, generally for establishing resource inventories and the identification of sites of particular conservation value. The refinement of this approach has been to use numerical techniques to establish differences in habitat type, e.g. on Argentinean marshes (Cantero et al., 1998) and on the Mississippi River deltaic plain (Visser et al., 1998). Such arguments have to some extent been driven by the Clementsian theory of deterministic, unidirectional change in ecosystem development (Clements, 1916) where plants are the primary drivers in trapping and binding sediments in intertidal environments and through determining elevation change, further control plant succession (and see Chapman, 1959 for a saltmarsh example). However, it is now clear that this is only one model for coastal classification, largely restricted to lowlying coasts with abundant sediment supply. Broader classifications for coastal mangroves for instance, have identified multiple categories for mangrove forests (Woodroffe, 1990) where geomorphical setting and the process environment differentiate between types. Such broad findings are also supported by research on the morphodynamics of tidally-dominated saltmarshes (Reed \& French, 2001). The key to a robust classification of coastal types is therefore to establish the physical contexts within which different wetland types are found. This means that for the assessment of wetland vulnerability, a morphological classification (Woodroffe, 2002) into wetland settings and their structural/physical characteristics is of more value. Taking this view, six broad wetland types were identified as the basis of transition and loss within the Wetland Change Model (Table 2).

Building on this classification, various response times associated with each wetland type were determined. Table 3 outlines the continuum of response times which define ecological lag effects within the model. Many saltmarsh plant species, for example, can tolerate a wide range of inundation frequencies (and the variations in physical

Table 2 The classification of wetland type used within the Wetland Change Model

1. Coastal forested wetlands

2. Freshwater marsh

3. Saltmarsh

4. Mangrove

5. Unvegetated sediment $>$ mean high water springs (sabkas)

6. Unvegetated sediment $<$ mean high water springs (mud and sand flats)

Table 3 Relative response lags within the Wetland Change Model

Coastal forested wetlands

Mangrove

Freshmarsh/Saltmarsh

Unvegetated sediment
Highest response lag

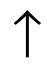

Lowest response lag 
and chemical soil characteristics which accompany them) and can rapidly colonise a range of new tidal habitats. By comparison, coastal forest tolerances are typically lower and colonisation of new habitat is difficult. For this habitat type, response will be strongly influenced by previous conditions, until a threshold point is reached when the system may collapse catastrophically (Cahoon et al., 2003). The relative response times of each wetland type were based on expert judgement combined with field observations. Incorporating response lag into the model transforms the assessment of the vulnerability of the total wetland area into a value of the ecological sensitivity of the six wetland types to sea-level rise (Fig. 1).

\section{Differentiation of wetland loss by wetland type}

Existing large-scale models of wetland response to accelerated sea-level rise generally deal with the conversion of vegetated surfaces to open water and thus generate statistics on total loss of wetland area, e.g. GVA and subsequent revisions (Nicholls et al., 1999). Such models are most appropriate where local rates of relative sea-level rise are high, such as in subsiding, sedimentstarved deltaic environments. However, under more moderate rates of sea-level rise and an adequate sediment supply ecosystem change may be (i) slower than predicted and (ii) involve change stepped across wetland types rather than simple loss, as ecological tolerances are exceeded in turn. The Wetland Change Model assesses both net wetland losses (due to conversion to open water) and transitions to other wetland types due to sea-level rise.

Linking the relative ecological sensitivities of wetland types to rates of wetland loss and transitions given sea-level rise requires (i) the construction of a series of wetland response curves (Fig. 3) which define the behaviour of the system by modelling the proportion of wetland expected to convert to another type given increasing exposure of a region to sea-level rise; and (ii) a model of wetland transition where loss is distributed between the wetland transitional types (Fig. 4).

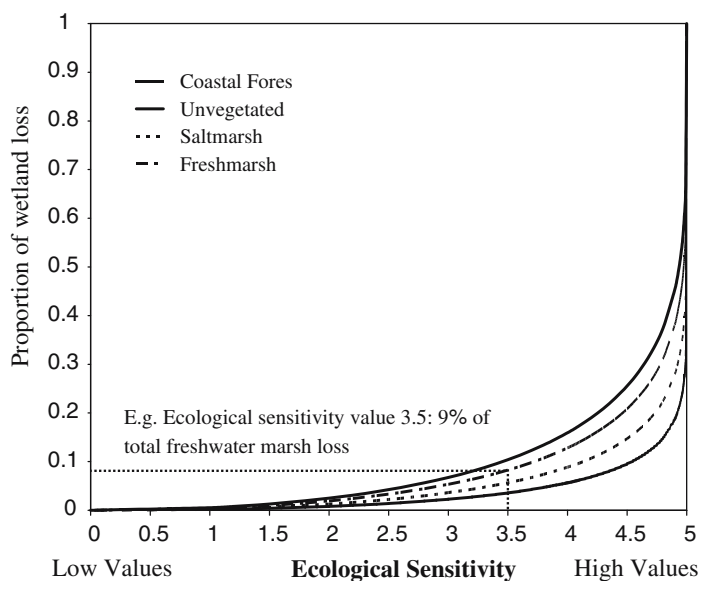

Fig. 3 Wetland loss, and wetland types as a proportion of total wetland loss, with changing wetland sensitivity (see text for explanation of ecological sensitivity)

Given the lack of information on broad-scale wetland behaviour, in the first instance both the wetland response curves and the transitional model were based on provisional estimates of wetland loss derived from expert judgement. Two primary datasets were used for calibration: (i) forecasting of changing wetland and open water areas in the Barataria and Terrebonne basins of South East Louisiana, USA from a basis of historical data collected by the United States Fisheries and Wildlife Service (USFWS) (D.J. Reed, pers. comm., 2003) and (ii) predictions of wetland type transitions produced by large-scale landscape modelling in the same region (Reyes et al., 2000). The Reyes model was initialised with the 1956 USFWS habitat map for the two basins and the results of a 32-year simulation compared against the 1988 map of the region (Reyes et al., 2000). Simulated maps showed a goodness-of-fit of $75 \%$ using a multiple resolution fit algorithm. The model was then run to the year 2018 under a range of scenarios.

The rate of increase in open water is a useful and readily definable summary measure of wetland loss. Table 4 shows the increase in the proportion of open water for the period 2000 2060 for four US Gulf Coast administrative units, calculated within the DIVA Wetland Change Model using the highest level of modelled sealevel forcing (1.07 m, 1990-2100) available from 
Fig. 4 Wetland loss and transitions between wetland types, to open water under sea-level rise: the Wetland Change Model
High forcing

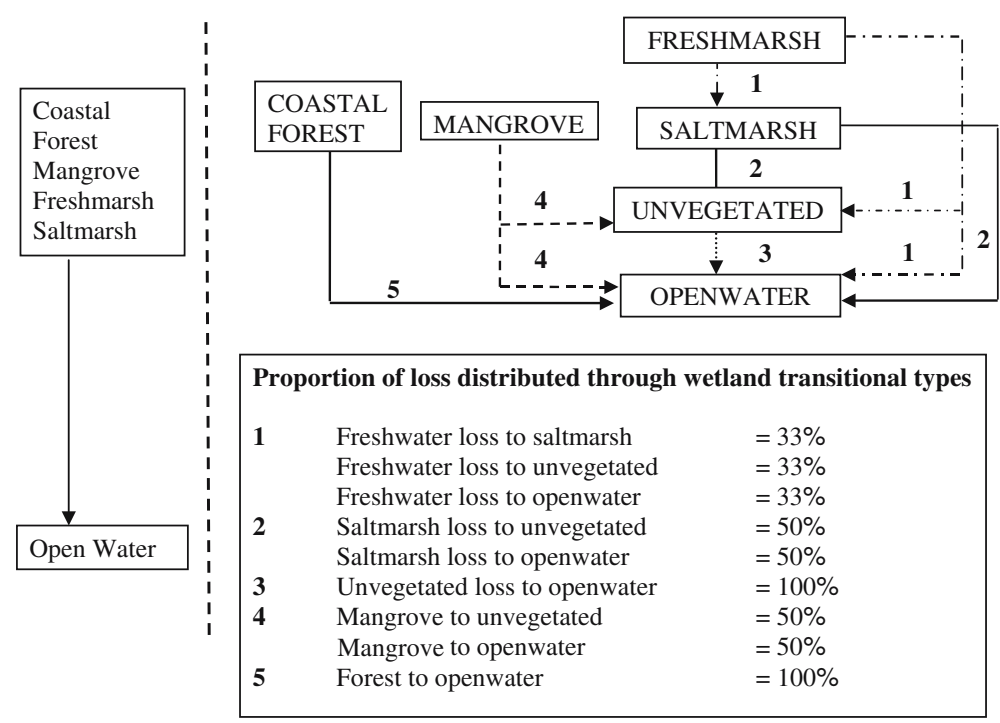

the Model. These data compare well with Reed's predictions of changes in the extent of open water in the Barataria and Terrebonne basins, with a similar timeframe and sea-level rise scenario.

The role of landscape modelling outputs (Reyes et al., 2000) within the DIVA calibration was two-fold. In the first instance, the results were used as a guide to the relative positions of the response curves within the envelope of vegetated wetland (Fig. 3). Outputs from the model were re-classified into the DINAS-COAST typology (Fig. 5) and basic trends in wetland loss were identified: the increase in open water at the expense of freshwater/brackish marsh and saltmarsh and the greater sensitivity of fresh marsh to sea-level forcing than saltmarsh within the basins. Less expected was the resilience of coastal forest which some authors (e.g. Conner \& Day, 1988) have suggested might disappear from the Mississippi delta altogether, with continuous flooding preventing seedling establishment.

The landscape modelling data also provides some calibration of the point at which the model of wetland transition changes from gradual transition between types to complete submergence (Fig. 4). With lower forcing, transitions to other wetland types reflect gradual changes as salinity levels increase and environmental thresholds are crossed. At the present time, the model distributes wetland loss in equal proportions through the

Table 4 DIVA predictions of wetland conversion to open water in 4 US Gulf Coast States compared with predicted wetland/open water transition data for two basins in the Mississippi Delta (from Reed, pers. comm., 2003)

\begin{tabular}{|c|c|c|c|c|c|c|}
\hline & \multicolumn{4}{|c|}{ DIVA Wetland Change Model parameters } & \multicolumn{2}{|c|}{$\begin{array}{l}\text { Reed (pers. comm., } \\
\text { 2003) }\end{array}$} \\
\hline & \multicolumn{4}{|c|}{ DIVA Administrative Units (Digital Chart of the World, ESRI, 2002) } & \multirow[t]{2}{*}{ Barataria } & \multirow[t]{2}{*}{ Terrebonne } \\
\hline & Texas & Louisiana & Alabama & Florida & & \\
\hline Coastal slope & Low forcing & Low forcing & Low forcing & Low forcing & & \\
\hline Tidal range & Low forcing & Low forcing & Low forcing & Low forcing & & \\
\hline Sediment supply & $\begin{array}{l}\text { Moderate-high } \\
\text { forcing }\end{array}$ & $\begin{array}{l}\text { Moderate-high } \\
\text { forcing }\end{array}$ & $\begin{array}{l}\text { Moderate-high } \\
\text { forcing }\end{array}$ & $\begin{array}{l}\text { Moderate-high } \\
\text { forcing }\end{array}$ & & \\
\hline $\begin{array}{l}\text { Increase in open water } \\
2000-2060\end{array}$ & $37 \%$ & $26 \%$ & $26 \%$ & $32 \%$ & $35 \%$ & $23 \%$ \\
\hline
\end{tabular}


Fig. 5 Model outputs from Reyes et al. (2000) for the Barataria (a) and Terrebonne (b) basins, Mississippi delta, reclassified into the DINAS-COAST wetland typology

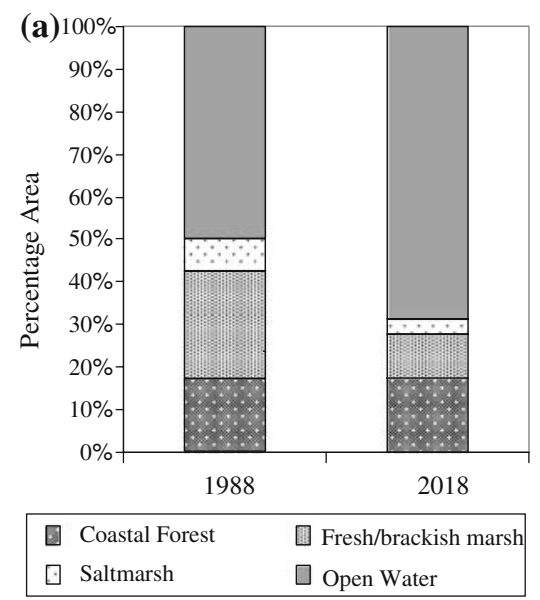

successive wetland types. However, under high levels of environmental forcing (high sea-level rise, low sediment supply and construction of barriers to horizontal wetland migration), the model converts all wetland losses to open water. The potential of the DIVA Wetland Change Model can be illustrated by the application of the model to another of the US Gulf Coast administrative units, the State of Florida (Fig. 6). The Model predicts an increase in open water from $2 \%$ in 2000 to $33 \%$ in 2060 , largely at the expense of tidal flat environments but with some loss of saltmarsh and freshwater marsh. The resilience of coastal forest should be noted and that of mangrove forest, although as sea-level rise accelerates so mangrove areas begin to decrease.

The results from the DIVA Wetland Change Model appear commensurate with general esti- mates of global wetland losses given accelerated near-future sea-level rise. Nicholls et al. (1999), for example, have estimated that $22 \%$ of the world's wetlands could be lost by 2080 given a rise in global sea level of $38 \mathrm{~cm}$. Table 5 shows the predicted loss of global wetlands over the time period 2000-2080 with low forcing scores for sediment supply and accommodation space under two sea-level rise scenarios. Although the model can predict regional to global vulnerability, a number of challenges remain, particularly when downscaling to regions where local effects may over-ride broad-scale controls. The development of more systematic national to regional scale assessments of wetland loss would further refine these estimates by contributing significantly to calibrating broad-scale models of the type presented here.
Fig. 6 Scenario of predicted wetland transitions 2000-2060 within the State of Florida, USA as predicted by the DIVA Wetland Change Model

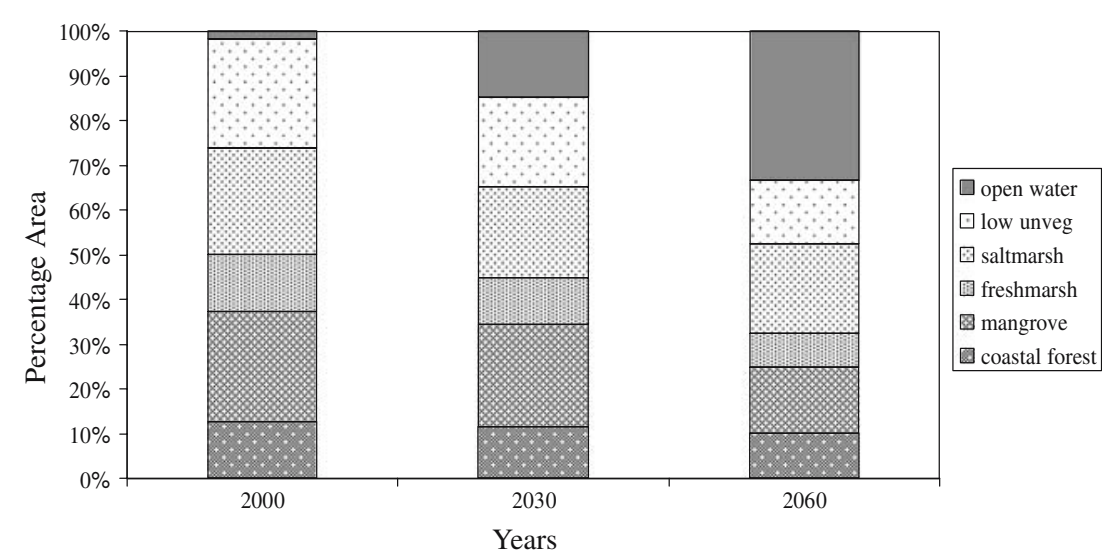


Table 5 Predicted global wetland losses 2000-2080 under two sea-level rise scenarios

\begin{tabular}{ll}
\hline & $\begin{array}{l}\text { Proportion of global wetlands lost, } \\
\text { 2000-2080 }\end{array}$ \\
RSLR-0.5 m & \\
$(1990-2100)$ & \\
2020 & 0.10 \\
2050 & 0.22 \\
2080 & 0.32 \\
RSLR-1 m & \\
$(1990-2100)$ & \\
2020 & 0.17 \\
2050 & 0.32 \\
2080 & 0.44 \\
\hline
\end{tabular}

\section{Conclusions}

The Wetland Change Model is an improved broad-scale model of loss and transition of coastal wetlands under sea-level rise. It incorporates all the primary drivers of wetland behaviour and provides an integrated perspective on the potential for wetland loss, examining a range of physical and human forcing parameters.

The major challenge lies in the validation of the model results. This is difficult at present due to the lack of suitable data and truly quantitative models of broad-scale wetland loss. The development of more systematic national to regional scale assessments of wetland behaviour would contribute significantly to validating the DIVA Wetland Change Model and hence, refining broad-scale estimates of wetland loss.

This work is in progress. As the model is applied and tested within DIVA it will inevitably be refined and improved. It is also hoped that this broad-scale modelling of coastal wetlands will stimulate improvements in, and extension of, field measurements of wetland behaviour, such that the data required to valid this type of model becomes more widely available.

Acknowledgements The authors gratefully acknowledge funding from the European Union under contract number EVK2-2000-22024. They thank all their partners in the DINAS-COAST project, particularly Z.B. Wang (Delft Hydraulics). We are grateful to Denise Reed, University of New Orleans, for directing us to the historical data on large-scale changing wetland and open water areas in the Barataria and Terrebonne basins, Mississippi delta, collected by the United States Fisheries and Wildlife Service (USFWS).

\section{References}

Allen, J. R. L., 1990. Salt-marsh growth and stratification: a numerical model with special reference to the Severn Estuary, southwest Britain. Marine Geology 95: 77-96.

Allen, J. R. L., 2000. Morphodynamics of Holocene salt marshes: a review sketch from the Atlantic and Southern North Sea coasts of Europe. Quaternary Science Reviews 19: 1155-1231.

Cahoon, D. R. \& D. J. Reed, 1995. Relationships among marsh surface topography, hydroperiod and soil accretion in a deteriorating Louisiana salt marsh. Journal of Coastal Research 11: 357-369.

Cahoon, D. R., P. Hensel, J. Rybczyk, K. L. McKee, C. E. Proffitt \& B. A. Perez, 2003. Mass tree mortality leads to mangrove peat collapse at Bay Islands, Honduras after Hurricane Mitch. Journal of Ecology 91: 10931105.

Cantero, J. J., R. Leon, J. M. Cisneros \& A. Cantero, 1998. Habitat structure and vegetation relationships in central Argentina salt marsh landscapes. Plant Ecology 137: 79-100.

Chapman, V. J., 1959. Studies in saltmarsh ecology. IX. Changes in the saltmarsh vegetation at Scolt Head Island. Journal of Ecology 47: 619-639.

Christiansen, T., P. L. Wiberg \& T. G. Milligan, 2000. Flow and sediment transport on a tidal salt marsh surface. Estuarine, Coastal and Shelf Science 50: 315-331.

Clements, F., 1916. Plant Succession: An Analysis of the Development of Vegetation. Carnegie Institute Publication 242, Washington DC.

Conner, W. H. \& J. W. Day, 1988. Rising water levels in coastal Louisiana: implications for two coastal forested wetland areas in Louisiana. Journal of Coastal Research 4: 589-596.

Day, J. W., J. F. Martin, L. Cardoch \& P. H. Templet, 1997. System functioning as a basis for sustainable management of deltaic ecosystems. Coastal Management 25: 115-153.

Day, J. W., J. Rybczyk, F. Scarton, A. Rismondo, D. Are \& G. Cecconi, 1999. Soil accretionary dynamics, sealevel rise and the survival of wetlands in Venice Lagoon: A field and modeling approach. Estuarine Coastal and Shelf Science 49: 607-628.

Environmental Systems Research Institute (ESRI), 2002. Digital Chart of the World (DCW). ESRI, Redlands, California.

French, J. R., 1993. Numerical simulation of vertical marsh growth and adjustment to accelerated sea-level rise, North Norfolk, UK. Earth Surface Processes and Landforms 18: 63-81.

French, J. R. \& T. Spencer, 1993. Dynamics of sedimentation in a tide-dominated backbarrier salt marsh, Norfolk, UK. Marine Geology 110: 315-331.

French, J. R. \& T. Spencer, 2002. Sea level rise. In Warren, A. \& J. R. French (eds), Habitat Conservation: 
Managing the Physical Environment. J. Wiley, Chichester, 305-347.

French, J. R., T. Spencer, A. L. Murray \& N. A. Arnold, 1995. Geostatistical analysis of sediment deposition in two small tidal wetlands, Norfolk, UK. Journal of Coastal Research 10: 308-321.

Hammar-Klose, E. S. \& E. R. Thieler, 2001. Coastal vulnerability to sea-level rise: a preliminary database for the U.S. Atlantic, Pacific and Gulf of Mexico coasts. U.S. Geological Survey, Digital Data Series DDS-68.

Harmsworth, G. C. \& S. P. Long, 1986. An assessment of saltmarsh erosion in Essex, England, with reference to the Dengie Peninsula. Biological Conservation 35: 377-387.

Hinkel, J. \& R. J. T. Klein, 2003. DINAS-COAST: Developing a Method and a Tool for Dynamic and Interactive Vulnerability Assessment. IGBP LOICZ Newsletter, 27 (June 2003), 1-4.

Hoozemans, F. M. J., M. Marchand \& H. A. Pennekamp, 1993. A Global Vulnerability Analysis: Vulnerability Assessment for Population, Coastal Wetlands and Rice Production on a Global Scale, 2nd edn. Delft Hydraulics, Delft, The Netherlands.

Koch, M. S., I. A. Mendelssohn \& K. L. McKee, 1990. Mechanism for the hydrogen sulphide-induced growth in a Juncus-roemerianus marsh, west-central Florida. Journal of Coastal Research 11: 322-336.

Martin, J. F., E. Reyes, G. P. Kemp, H. Mashriqui \& J. W. Day, 2002. Landscape modelling of the Missippi delta. Bioscience 54: 357-365.

McFadden, L., R. J. Nicholls, A. T. Vafeidis \& R. S. J. Tol (in press). A methodology for modelling coastal space for global assessment. Journal of Coastal Research.

Mendelssohn, I. \& J. T. Morris, 2000. Ecophysiological controls on the growth of Spartina alterniflora. In Weinstein M. A. \& D. Kreeger (eds), Concepts and Controversies in Tidal Marsh Ecology. Kluwer, New York.

Middleton, B. A. \& K. L. McKee, 2001. Degradation of mangrove tissues and implications for peat formation in Belizean island forests. Journal of Ecology 89: 818828 .

Mitsch, W. J. \& J. W. Day, 2004. Thinking big with whole ecosystem studies and ecosystem restoration - the legacy of H.T. Odum. Ecological Modelling 178: 133155.

Mitsch, W. J. \& J. G. Gosselink, 2000. Wetlands. J. Wiley, New York.

Morris, J. T., P. V. Sundareshwar, C. T. Nietch, B. Kjerfve \& D. R. Cahoon, 2002. Responses of coastal wetlands to rising sea level. Ecology 83: 2869-2877.

Nicholls, R. J., F. M. J. Hoozemans \& M. Marchand, 1999. Increasing flood risk and wetland losses due to global sea-level rise: regional and global analyses. Global Environmental Change 9: S69-S87.
Nyman, J. A., R. D. DeLaune, S. Pezeshki \& W. H. Jr. Patrick, 1995. Organic matter fluxes and marsh stability in a rapidly submerging estuarine marsh. Estuaries 18: 207-218.

Oenema, O. \& R. D. DeLaune, 1988. Accretion rates in saltmarshes in the eastern Scheldt, southwest Netherlands. Estuarine, Coastal and Shelf Science 26: 379 394.

Oueslati, A., 1992. Salt marshes in the Gulf of Gabes (south eastern Tunisia): their morphology and recent dynamics. Journal of Coastal Research 8: 727-733.

Phillips, J. D., 1986. Coastal submergence and marsh fringe erosion. Journal of Coastal Research 2: 427-436.

Poff, L. F., N. M. Brinson \& J. W. Jr. Day, 2002. Aquatic ecosystems and global climate change: potential impacts on inland freshwater and coastal wetland ecosystems. Pew Center for Global Climate Change, Arlington, VA.

Reed, D. J., 1988. Sediment dynamics and deposition in a retreating coastal salt marsh. Estuarine Coastal and Shelf Science 26: 67-79.

Reed, D. J., 1995. The response of coastal marshes to sealevel rise: survival or submergence? Earth Surface Processes and Landforms 20: 39-45.

Reed, D. J. \& J. R. French, 2001. Physical contexts for saltmarsh conservation. In A. Warren \& J. R. French (eds), Habitat Conservation: Managing the Physical Environment. J. Wiley, Chichester, 67-104.

Reyes, E., J. L. White, J. F. Martin, G. P. Kemp, J. W. Day \& W. Aravamuthan, 2000. Landscape modeling of coastal habit change in the Mississippi delta. Ecology 81: 2331-2349.

Rooth, J. E., J. C. Stevenson \& J. C. Cornwell, 2003. Increased sediment accretion rates following invasion by Phragmites australis: The role of litter. Estuaries 26: 475-483.

Schwimmer, R. A. \& J. E. Pizzuto, 2000. A model for the evolution of marsh shorelines. Journal of Sedimentary Research 70: 1026-1035.

Stevenson, J. C., L. G. Ward \& M. S. Kearney, 1986. Vertical accretion in marshes with varying rates of sea level rise. In Wolfe D. A. (ed.), Estuarine Variability. Academic Press, Orlando, 241-259.

Vafeidis, A. T., R. J. Nicholls, L. McFadden, J. Hinkel \& P. S. Grashoff, 2004. Developing a Global Database for Coastal Vulnerability Analysis: Design Issues and Challenges. The International Archives of Photogrammetry, Remote Sensing and Spatial Information Sciences, Vol. XXXV Part B.

Visser, J. M., C. E. Sasser, R. H. Chabreck \& R. G. Linscombe, 1998. Marsh vegetation types of the Mississippi River Deltaic Plain. Estuaries 21: 818-828.

Woodroffe, C. D., 1990. The impact of sea level rise on mangrove shorelines. Progress in Physical Geography 14: 483-520.

Woodroffe, C. D., 2002. Coasts: Form, Process and Evolution. Cambridge University Press, Cambridge. 